\title{
Article \\ Bandung Rainfall Forecast and Its Relationship with Niño 3.4 Using Nonlinear Autoregressive Exogenous Neural Network
}

\author{
Resa Septiani Pontoh ${ }^{1, * \mathbb{D}}$, Toni Toharudin ${ }^{1} \mathbb{D}$, Budi Nurani Ruchjana ${ }^{2} \mathbb{D}$, Novika Sijabat ${ }^{1} \mathbb{D}$ and \\ Mentari Dara Puspita ${ }^{1}$ (D) \\ 1 Department of Statistics, Faculty of Mathematics and Natural Sciences, Universitas Padjadjaran, \\ Sumedang 45363, Indonesia; toni.toharudin@unpad.ac.id (T.T.); novika18001@mail.unpad.ac.id (N.S.); \\ mentari18001@mail.unpad.ac.id (M.D.P.) \\ 2 Department of Mathematics, Faculty of Mathematics and Natural Sciences, Universitas Padjadjaran, \\ Sumedang 45363, Indonesia; budi.nurani@unpad.ac.id \\ * Correspondence: resa.septiani@unpad.ac.id
}

check for updates

Citation: Pontoh, R.S.; Toharudin, T.; Ruchjana, B.N.; Sijabat, N.; Puspita, M.D. Bandung Rainfall Forecast and Its Relationship with Niño 3.4 Using Nonlinear Autoregressive Exogenous Neural Network. Atmosphere 2022, 13, 302. https://doi.org/10.3390/ atmos13020302

Academic Editors: Baojie He, Ayyoob Sharifi, Chi Feng and Jun Yang

Received: 13 January 2022 Accepted: 4 February 2022 Published: 10 February 2022

Publisher's Note: MDPI stays neutral with regard to jurisdictional claims in published maps and institutional affiliations.

Copyright: (C) 2022 by the authors. Licensee MDPI, Basel, Switzerland. This article is an open access article distributed under the terms and conditions of the Creative Commons Attribution (CC BY) license (https:// creativecommons.org/licenses/by/ $4.0 /)$.

\begin{abstract}
The city of Bandung, as the capital city of West Java, is one of several areas in Indonesia with high rainfall. This situation can cause disasters, such as floods and landslides, that can harm many parties. Rainfall in Indonesia, particularly on the island of Java itself, is closely related to the global phenomenon of Niño 3.4. In the period from January 2001-November 2021, the rainfall and Niño 3.4 showed some extreme values. In order to foresee the disasters, an accurate rainfall forecast should be performed. For this reason, we try to construct a model of rainfall forecast and its relation to the global phenomenon of Niño 3.4 using the nonlinear autoregressive exogenous neural network (NARX NN). The result shows that NARX NN (13-7-1) with a Mean Absolute Percentage Error (MAPE) value of $6.26 \%$ and $R^{2}$ of $85.37 \%$ is best suited for the prediction of this phenomenon. In addition, this study provides forecast results for the next six periods, which can be used as a reference for the relevant authorities to foresee the possibility of flooding in Bandung city. From the forecast results, it can be concluded that the highest rainfall forecasts in the city of Bandung are in February 2022, and will slowly decrease in March 2022. To prevent hydro-meteorological disasters, such as floods in Bandung city, the community can clear waterways, such as clogged drains, rivers, and dams, as well as prepare tools for evacuation.
\end{abstract}

Keywords: rainfall; Bandung; Niño 3.4; NARX NN

\section{Introduction}

The earth is a habitat and a place to live for various creatures in the world, including humans. However, due to global warming, the earth is becoming hotter by the day. Global warming is one of the most important environmental issues facing the world today. Global warming is a form of ecosystem imbalance on earth due to the process of increasing the average temperature of the earth's atmosphere, sea, and land [1]. The effects of global warming cause climate change. Climate change is characterized by the frequent occurrence of extremely high temperatures [2]. This leads to natural disasters [3], such as floods, which have severe socio-economic impacts [4]. Therefore, the early detection of climate change is necessary for the prevention of disasters that harm people.

Indonesia is a maritime country located at the equator and flanked by two large oceans, namely the Pacific and the Indian Ocean and two large continents, namely the Asian and the Australian continent [5]. This geographical location causes the weather and climate in Indonesia to be very dynamic and complex [6]. Abnormal weather and climate conditions often occur in Indonesia, which is caused by various global climate phenomena, such as the Asia-Australia monsoon, Indian Ocean Dipole (IOD), El Niño, east-west circulation (Walker circulation), and north-south circulation (Hadley circulation), as well as some circulations due to local influences [7]. The authors of [8,9] conducted a research study 
that links the role of global phenomena, namely ENSO, IOD, and monsoon variability, to precipitation, temperature, and humidity in Myanmar, a monsoon region. Indonesia itself is an area affected by the monsoon.

El Niño-Southern Oscillation (ENSO) is an east-west circulation that occurs in the equatorial Pacific Ocean [10]. The interaction of the atmosphere and oceans causes an increase and decrease in sea surface temperature that exceed the 30-year long-term average temperature, and thus deviations occur. If the deviation is positive, then the sea surface temperature will rise or commonly called El Niño, whereas if the deviation is negative, then the sea surface temperature will decrease or commonly called La Niña [11].

The occurrence of El Niño and La Niña is affected by shifts in the Walker circulation. The Walker circulation is an atmospheric circulation, in which convection centers or warm "pools" in the western and eastern Pacific are displaced [12]. In the El Niño incident, the Walker circulation center (convection center) was shifted from the warm "pool" area in the north of the island of Papua to the more eastern region in the central Pacific. As a result, wind movements occur in Indonesia and the surrounding area, which are characterized by a very drastic reduction in precipitation. At La Niña events, the Walker circulation increases with a larger convection center in the western Pacific and stronger wind exchange. As a result, Indonesia and the surrounding area saw an increase in rainfall [13].

ENSO values refer to the Southern Oscillation index (SOI), Niño 2, Niño 3, Niño 4, Niño 3.4, and Ocean Niño index (ONI) [14]. In a study conducted by Kartika Nur Anisa, the Niño 3.4 index was stated as the best ENSO indicator in identifying the rainfall relationship in Indonesia [15]. Therefore, in this study, the Niño 3.4 input series is used to predict rainfall.

The city of Bandung, as the capital of West Java, has a strategic position and role with a large amount of potential for development in economic, agricultural, and tourism aspects [16]. The development of this potential is influenced by the location of the city of Bandung. Geographically, the city of Bandung city is located at coordinates $107036^{\prime}$ east longitude and $6055^{\prime}$ south latitude [17]. Meanwhile, topographically, the city of Bandung is located at an average altitude of $791 \mathrm{~m}$ above sea level (asl), the highest point in the north with an altitude of $1050 \mathrm{~m}$ and the lowest in the south with an altitude of $675 \mathrm{~m}$ above sea level [17]. The map of the city of Bandung is shown in Figure 1.

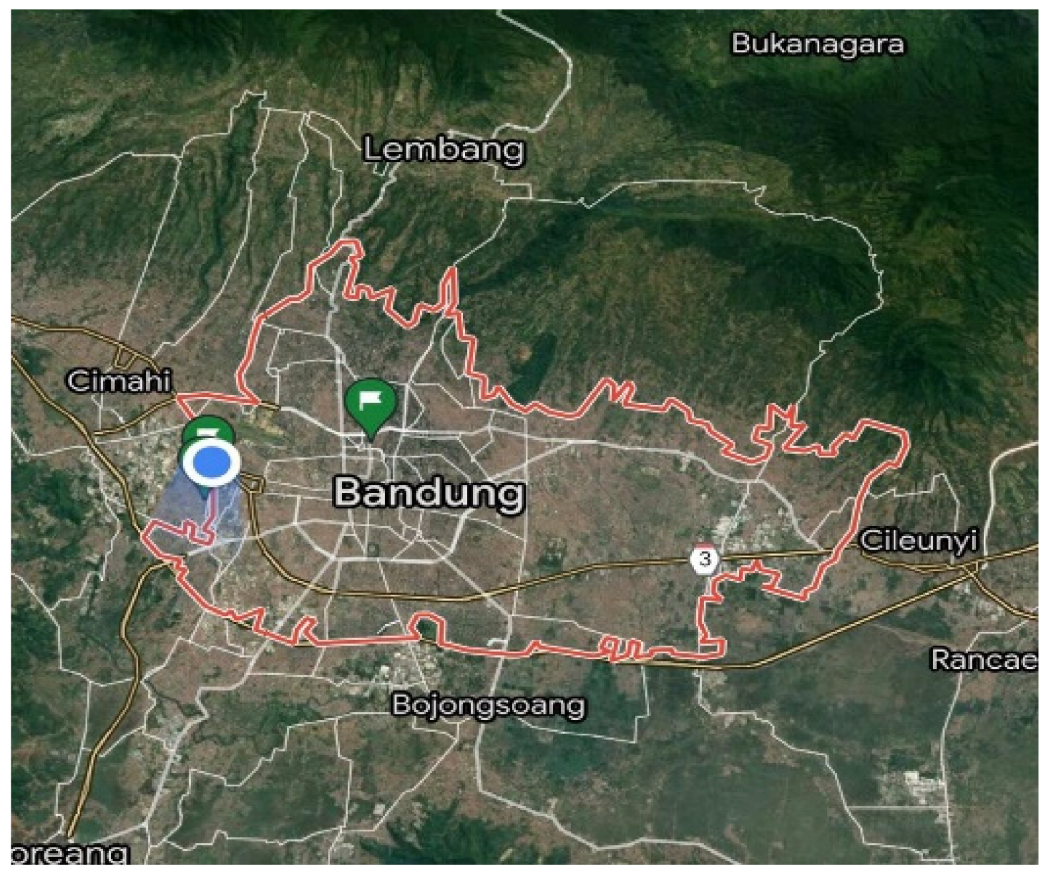

Figure 1. Map of Bandung City. Source: https:/ / maps.google.com (accessed on 2 February 2022). 
In particular, the northern part of the city of Bandung is a hilly area. Therefore, by reviewing the topographical and geographical aspects, we can easily conclude that the area of Bandung city is the upstream part of the drainage system, which will contribute runoff water to the downstream part of Bandung city. In Figure 1, it can be seen that the city of Bandung is an area with a humid mountainous climate and high rainfall. Rain with high intensity can cause disasters, such as floods and landslides, that can harm many parties [18].

In December 2007, the heavy rainfall caused flash floods in the district of Cidadap, Bandung [19]. Then, in November 2016, there were floods at 16 points in the city of Bandung, including Pagarsih, Pasirkaliki, Wastukancana, Lodaya, Pasirkoja, A. Yani, Sukagalih, Sudirman, Waringin (Andir market), Laswi, Burangrang, Eastern Railway Station, Kebon Jati, Caringin, Otista, and Jalan dr. Djundjunan. Moreover, the flood overwhelmed several public institutions, such as the Bandung railway station, the Bandung Cicendo Eye hospital, and shops on Jalan Lembong Merdeka [20]. In early and late 2018, Bandung city also suffered flooding. Due to heavy rains, several points overwhelmed Bandung city [21]. In February 2020, according to a report by the Bandung city regional disaster management agency (BPBD), floods in six subdistricts were caused by high precipitation factors in the Bandung city region [22].

Figure 2 shows a graph of the Niño 3.4 index data with rainfall in the period from January 2001-November 2021, with monthly precipitation data for Bandung city [23,24]. Visually, the Niño 3.4 data chart shows random data patterns with very strong fluctuating data movements. Moreover, the data have extreme values or values that are very different from other values. Meanwhile, the monthly precipitation data for Bandung city in the period from January 2001-November 2021 show the highest precipitation value in December 2007, November 2016, and November 2021, where precipitation exceeds $800 \mathrm{~mm} / \mathrm{month}$ and the lowest precipitation is $13.82 \mathrm{~mm} / \mathrm{month}$ in September 2019. From the rainfall data, it can be seen that the city of Bandung is an area with an average rainfall of 261.2495 $\mathrm{mm} /$ month. With this condition, it can be concluded that the city of Bandung has a significantly high amount of rainfall. Therefore, information regarding weather forecasts, especially rainfall, is required.

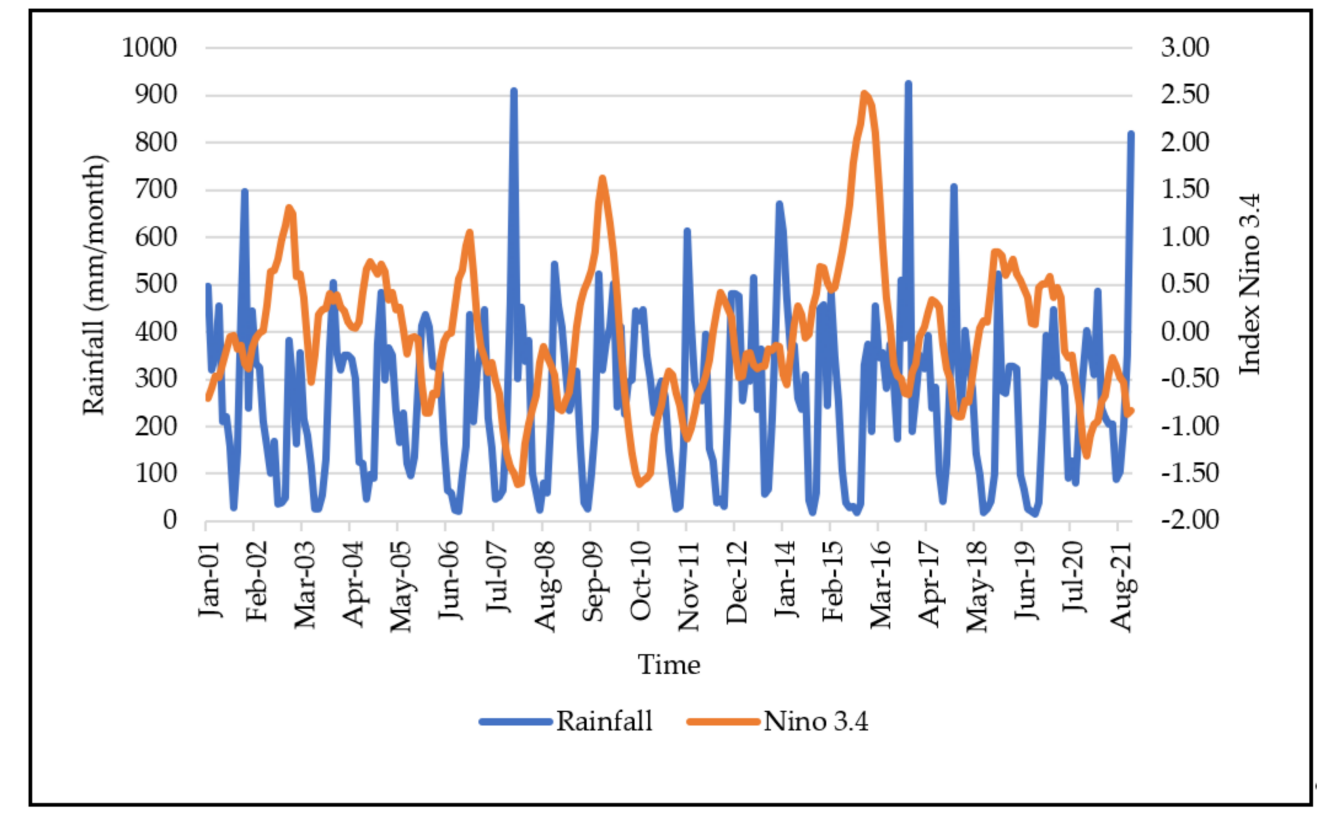

Figure 2. Graph of the Niño 3.4 index with rainfall in Bandung city in the period from January 2001-November 2021. Source: https://apcc21 (Niño 3.4) and https://iridl.ldeo.columbia.edu (rainfall) (accessed on 13 January 2022). 
Information regarding probable future rainfall can help in running the regional potential activities more efficiently, such as agriculture, plantations, aviation, tourism, public services, and natural disasters. Various managements use this information as a basis for planning, monitoring, and decision-making.

Current precipitation information can be obtained through the media. However, there are many methods that can be used for prediction or forecasting. In general, data prediction methods, such as precipitation forecast are based on time series data, and future forecasts are based on past data. This method creates a time series model from a series of observations or observations of events, events or variables that are measured in time series, for example, hours, daily, monthly, yearly, etc. In conjunction with the theory described, the Niño 3.4 series is a series that affects the prediction of precipitation. Therefore, it is necessary to conduct forecasts to predict the monthly precipitation, taking into account the influence of Niño 3.4 in the next periods of time. The analysis is carried out with a time series analysis method that can record extreme values. Therefore, the forecast results can be used as a reference for Regional Disaster Management Agency (BPBD) and the city administration of Bandung to initiate the assessment and anticipation steps in areas at risk of flooding. As a result, the time series analysis used in this study is NARX NN.

In Figure 2, the rainfall data in Bandung city shows a very strong fluctuating pattern, and there is a random pattern or changes every month. Therefore, we need a method that can capture random patterns from rainfall data, and then maps the effect of exogenous variables on the response variable. Based on the research on sea wave energy prediction [25], the artificial neural network method was found to be one of the right solutions for modeling with nonlinear relationships. In addition, the artificial neural network method has higher resistance (robust) against noise. The ANN method can learn and adapt data patterns through repeated learning. Therefore, it can be used for forecasting without the need for paying attention to the patterns from the original data [26].

Several previous studies have conducted rainfall forecasting using several other forecasting methods. The authors of [27] carried out rainfall forecasting using the hybrid wavelet artificial neural network (WANN) to predict rainfall in Queensland, Australia over a period of 1,3,6, and 12 months in advance. The RMSE values obtained are 90, 52, 32, and $15 \%$, respectively. Furthermore, the authors of [28] conducted research that concentrates on the ability of the ANN model in predicting several weather phenomena, such as rainfall, temperature, flooding, and tidal levels, etc. Finally, it has been concluded that the major architectures, namely BPN, RBFN, and MLP are best suited for the prediction of this weather phenomenon. In a comparative study between various ANN techniques, BPN and RBFN were found to be the right solution for long-term weather forecasting. The authors of [29] conducted research using the adaptive network based fuzzy inference system optimized with particle swarm optimization (PSOANFIS), artificial neural networks (ANN), and support vector machines (SVM) for the prediction of daily rainfall in Hoa Binh province, Vietnam. By adding the variables of maximum temperature, the minimum temperature, wind speed, relative humidity, and solar radiation are used as input variables. The results of the study show that all of the artificial intelligent (AI) models provide reasonable daily rainfall predictions. However, SVM was found to be the best method for the prediction of rainfall. Moreover, the authors of [30] carried out rainfall forecasting using eight statistical methods and machine learning. In this study, the results indicate that neural networks are found to perform best for the prediction of rainfall occurrence. Herein, the research has been conducted to explore the relationship between the atmospheric phenomena, including the Sunspot (SS), East Asian summer monsoon index (EASMI), ACI, South Asian summer monsoon index (SASMI), and the rainfall that occurs in Bangladesh [31].

The nonlinear autoregressive exogenous neural network (NARX NN) is a development method of ANN, in which there are additional exogenous variables to achieve better results. The nonlinear autoregressive neural network (NARX) method has been used in various studies, such as the research in [32], which predicts energy consumption in public buildings using nonlinear autoregressive (NAR) and nonlinear autoregressive neural 
network (NARX) methods. The NARX method uses historical temperature data as an exogenous variable. In this study, the data were split $70 \%$ for training data and $30 \%$ for test data. The MSE value obtained from the NAR method is 1.67, while the NARX method is 0.66. The NARX method uses the exogenous variable information to achieve better results.

The authors of [33] conducted research to compare the NARX method to other methods. This study compared the NARX method with ARIMAX in predicting wheat yield on Kanpur land in Uttar Pradesh by considering the weather variable, namely the maximum temperature at the critical root initiation (CRI) stage, as an exogenous variable. The research results showed that the NARX method outperformed the ARIMAX model in modeling and forecasting. The MAPE value obtained from the ARIMAX model is 2.93 and the value from the NARX model is 1.94. Research using NARX NN has also been carried out for the forecasting of the groundwater level for several wells in southwest Germany, involving exogenous variables, which are precipitation and temperature variables [34].

\section{Materials and Methods}

In this study, the data used are secondary data in the form of monthly historical data, which are derived from open data and extracted from the UCSB CHRIPS website (www.iridl.ldeo.columbia.edu, accessed on 13 January 2022) [23] and the APCC website (www.apcc21.org, accessed on 13 January 2022) [24]. In particular, precipitation data are the main variables and Niño 3.4 data are the exogenous variables. The time interval used for the precipitation data and Niño 3.4 starts in the period from January 2001-November 2021. There was no update from the UCSB CHRIPS website for the December 2021 data. The nonlinear autoregressive exogenous neural network (NARX NN) analysis was performed using the $\mathrm{R}$ software for the prediction of precipitation data.

The nonlinear autoregressive exogenous (NARX) is a nonlinear time series model with exogenous variable inputs. Exogenous variables are external variables that have an impact on the observed variables. Algebraically, the NARX model can be written as follows:

$$
y_{t}=f\left(y_{t-1}+y_{t-2}+\ldots+x_{t}+x_{t-1}+x_{t-2}+\ldots\right)+\varepsilon_{t},
$$

where $y$ is the main variable to be observed and $x$ is the exogenous variable that explains $y$ [35].

The artificial neural network (ANN), also referred to as neural network (NN), is an information processing system that works in the same way with biological neural networks [36]. According to the study in [26], the main benefit of NN is a flexible nonlinear modeling function. Modeling with NN does not require any specific initial model specifications. Instead, the model is built based on the properties of the data. One of the developments of the neural network prediction method is the NARX NN method. The NARX NN method is a nonlinear autoregressive method that uses the neural network (NN) function to predict time series data using additional exogenous variables (in addition to the main observed variables) to produce more accurate estimates [37,38]. Based on the network architecture, NARX NN is divided into two parts, namely the serial-parallel model, which is the feed-forward neural network (FFNN), and the parallel model, which is the recurrent neural network (RNN). In the series-parallel model, the future value of the time series $y_{t}$ is derived from the current and/or past values of $x_{t}$ and the actual past values of the time series $y_{t}[39]$.

The analysis stages were carried out on the basis of eight criteria:

1. Splitting data according to the rolling origin cross-validation (ROCV) series

Initially, prior to performing the procedures to form a network architecture, we need to split the data into two parts, namely data training and data testing. The purpose of data splitting is to collect the ideal amount of data for the training and exam process. Therefore, the obtained results are optimal. Testing data are usually around $20 \%$ of the amount of data in total, although their value can be changed depending on the length of the overall data and the forecast that will be conducted. The ideal amount of test data is at least as 
much as the length of the prediction to be performed [40]. The data released are carried out according to the ROCV series.

\section{Structure of the network architecture}

An architecture network is an arrangement of units in the coating and the pattern of the relationship between the layers. This research uses the NARX NN series-parallel model with feed-forward architecture. The multi-layer perceptron (MLP) is used in the NARX NN architecture since MLP has a structure, which can learn non-linear mapping. The steps required in forming a network architecture are the determination of the number of input units, the number of hidden layers, the number of hidden units, and the number of output units, which are used in the network. The unit input of the network NARX NN series-parallel model is the value of time $(t)$, the observed variable $(Y)$, and the exogenous variable $(X)$.

\section{Selection of the activation function}

The activation function is used in order to convert the input signal into an output signal of each unit in the hidden layer and the output layer. There are no specific rules in the selection of the activation function to be used. However, a non-linear activation function is required for multi-layer networks. Moreover, the activation function can be determined based on the algorithm in which the training was used. The activation function, which is used for the algorithm backpropagation, must be continuous, differentiable, and is a function which is not reduced in monotone. In this study, we will use tanh for the hidden activation function and linear activation function of the output layer.

$$
\begin{gathered}
f(x)=\frac{e^{x}-e^{-x}}{e^{x}+e^{-x}} \\
\text { or } f(x)=[1+f(x)][1-f(x)]
\end{gathered}
$$

\section{Normalization of data}

Prior to performing the training process, especially in the run-up to any normalization of data, the input data must be in the interval of the used activation function. The data can be normalized using the min-max scaling technique with the following formula:

$$
y_{i}^{\prime}=a+\frac{\left(y_{i}-y_{\min }\right)(b-a)}{y_{\max }-y_{\min }}
$$

where $y_{i}^{\prime}$ is the value of the data after normalization, $y_{i}$ is the original value of the data, $y_{\min }$ is the minimum value of the entire original data, $y_{\max }$ is the maximum value of the entire original data, $a$ is the minimum range value, and $b$ is the maximum range value.

\section{Implementation of training and testing processes}

The purpose of the training and testing process is to find the optimal specification model, which produces minimal errors. The training process is carried out using an algorithm and the most commonly used algorithm is backpropagation. The backpropagation algorithm has several development versions, one of which is resilient backpropagation (Rprop). Rprop is an algorithm with adaptive learning and convergence, which is faster than backpropagation. The Rprop algorithm is divided into two parts, namely Rprop without weight backtracking (Rprop-) and Rprop with weight backtracking (Rprop+). The difference is the so-called pullbacks, which indicate that if the sign derivative partial changes in the Rprop+ algorithm, then the amount of weight is directly reduced by the amount of change in the weight of the previous iteration. In this study, the training process was performed using an elastic backpropagation algorithm with weight backtracking $($ Rprop+).

\section{Evaluation of the forecast model from the MAPE value}

The process of training and testing is carried out for more network architectures with different hidden units. The model evaluation was conducted to find model specifications 
with certain hidden units, which produce minimal error. The size of the model error is calculated using MAPE from the prediction error value of each roll. MAPE can be calculated using the following formula:

$$
M A P E=\frac{1}{n} \sum_{t=1}^{n}\left|\frac{y_{t}-\hat{y}_{t}}{y_{t}}\right| \times 100 \%
$$

where the calculated value of $R^{2}$ shows how effective the models are in forecasting. The $R^{2}$ equation is as follows:

$$
R^{2}=\frac{\sum\left(\hat{y}_{t}-\bar{y}\right)^{2}}{\sum\left(y_{t}-\bar{y}\right)^{2}}
$$

\section{Prediction of exogenous variables}

The prediction of the exogenous variables can be carried out using a forecasting method that fits with the characteristics of the variables. In this study, the prediction was performed using FFNN.

\section{Prediction of main variables}

The NARX NN models, with the smallest error size corresponding to results of the evaluation, are used to predict the observed variables. Forecasting is accomplished with all of the current and combined data on a natural logarithmic scale. Since the results from the NARX NN model will have a value within the normalization interval on a natural logarithmic scale, it is necessary to de-normalize the results to obtain the original forecast value.

\section{Results}

\subsection{NARX NN Model Formation}

The NARX NN model was constructed using rainfall data as the observed variable and Niño 3.4 index data as the exogenous variable. Prior to the formation of the NARX NN model, the rainfall data were divided into training and testing data, while all of the Niño 3.4 index data were used as input for training the NARX NN model. Figure 2 shows the splitting of the training data (blue) and the testing data (green). Then, the NARX NN architecture is created. The number of hidden layers used is one layer. The number of hidden units used is determined by trial and error, where the number of hidden units creates the smallest error size. The number of output units used is one unit since the desired output is only one, which is the result of the rainfall forecast. The NARX NN rainfall model network architecture is shown in Table 1.

Table 1. NARX NN rainfall model network architecture.

\begin{tabular}{cc}
\hline Unit & Specifications \\
\hline Input unit & 13 units, consisting of lag $1,2, \ldots, 365$ from \\
Hidden layer & rainfall and the current value of Niño 3.4 index \\
Hidden unit & 1 layer \\
Output unit & $1,2,3,4,5,6,7$ unit (trial and error) \\
1 unit
\end{tabular}

Following the formation of the network architecture, the next stage is the process of training and testing the model evaluation. The rainfall data and Niño 3.4 index data used in the training process were first normalized using the min-max scaling technique with the values of $a=-0.8$ and $b=0.8$. The training process includes the determination activation functions and training algorithms. For the testing process, the network from the training process is used to forecast a period in advance. The training and testing processes were carried out for seven rainfall model network architectures with different hidden units. The training and testing processes of each network architecture are repeated with each rolling, 
as shown in Figure 3 (ROCV method). Then, the model is evaluated by calculating the MAPE value for each network architecture with certain hidden units. The results of trial and error of the seven network architectures with different numbers of hidden units can be seen in Table 2.

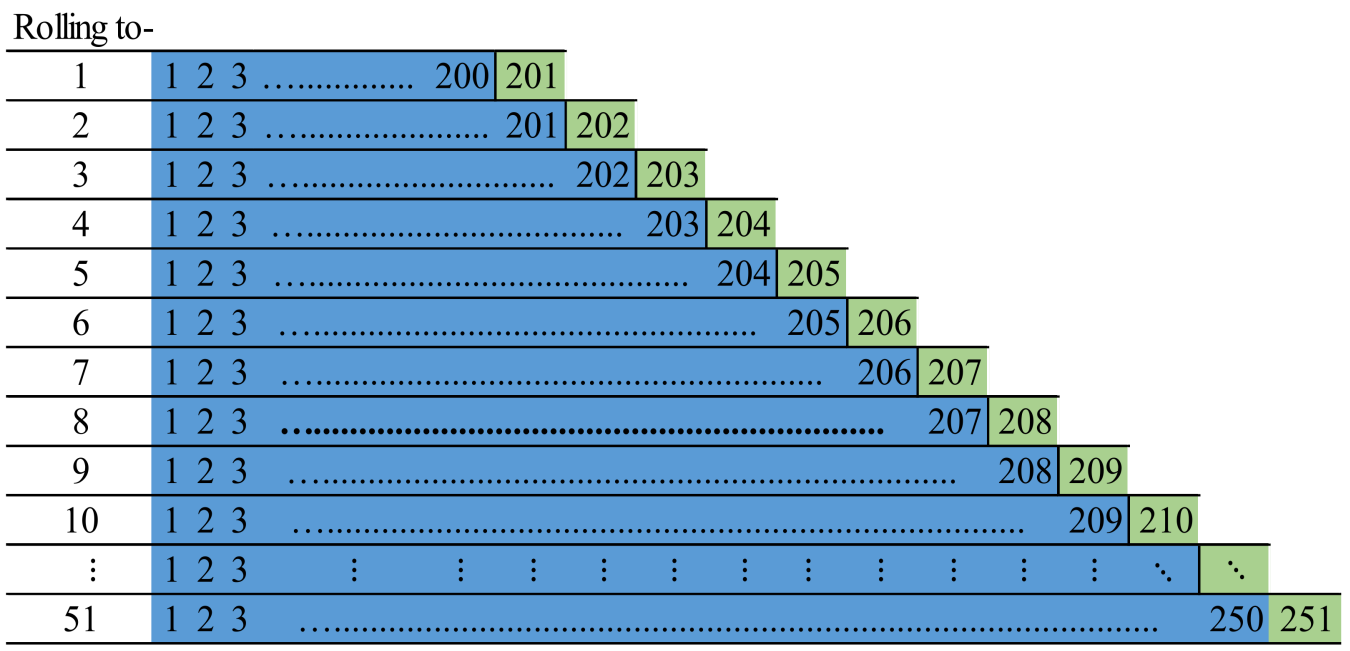

Figure 3. Rainfall data distribution.

Table 2. The error size of the NARX NN rainfall model.

\begin{tabular}{ccc}
\hline Architecture & Hidden Unit & MAPE Test \\
\hline & 1 & 6.399138 \\
& 2 & 6.935423 \\
Input unit $=13$ & 3 & 6.613024 \\
Hidden layer $=1$ & 4 & 6.587894 \\
& 5 & 6.809819 \\
& 6 & 6.857698 \\
& 7 & 6.259928 \\
\hline
\end{tabular}

In Table 2, it can be seen that the network architecture that generates the minimum error size is the architecture with thirteen input units, one hidden layer, seven hidden units, and one output unit or it can be seen as the NARX NN model (13-7-1) with a MAPE value of $6.26 \%$ and $R^{2}$ of $85.37 \%$. A visualization of the comparison result of the training process prediction with the test data according to the ROCV method can be seen in Figure 4 . The NARX NN (13-7-1) model is applied to all of the data and is used to predict rainfall data. The rainfall is known to be influenced by the Niño 3.4 index. Therefore, to achieve the rainfall forecast result, it is first necessary to forecast the Niño 3.4 index. 


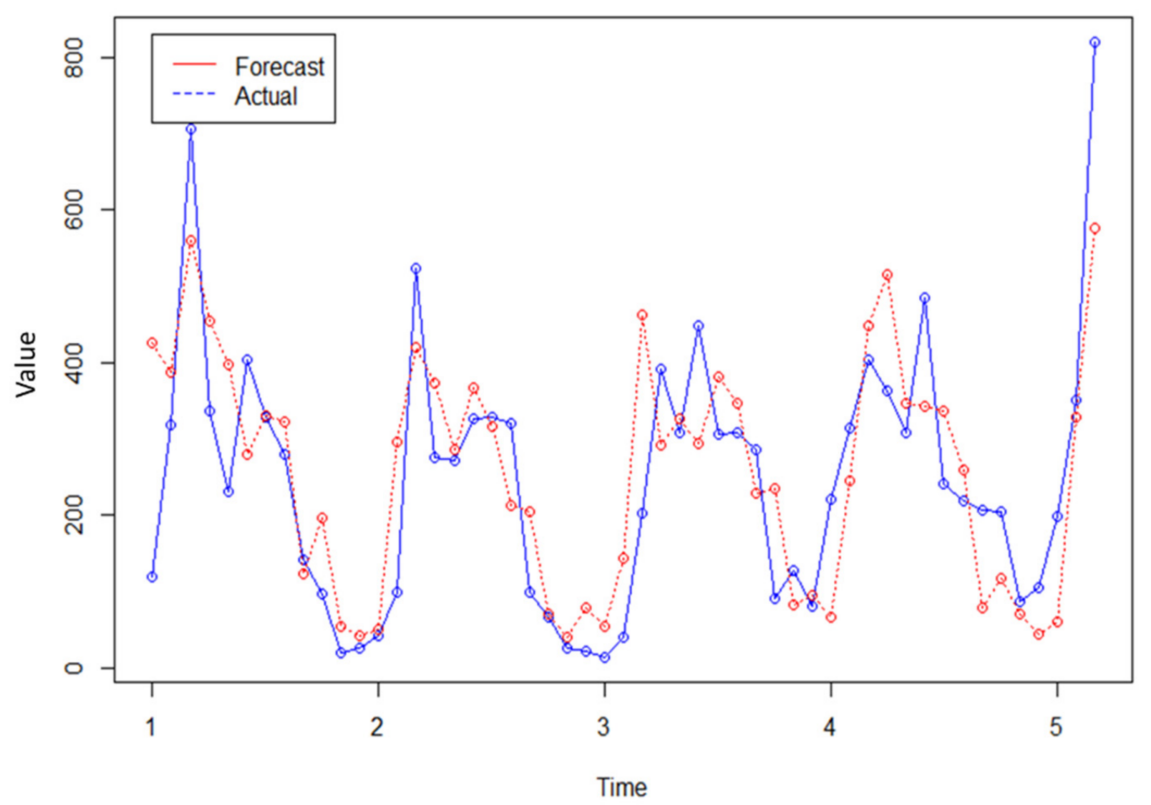

Figure 4. Graphically compare the forecast of the training process with rainfall data.

The network architecture visualization of the NARX NN model (13-7-1) is shown in Figure 5.

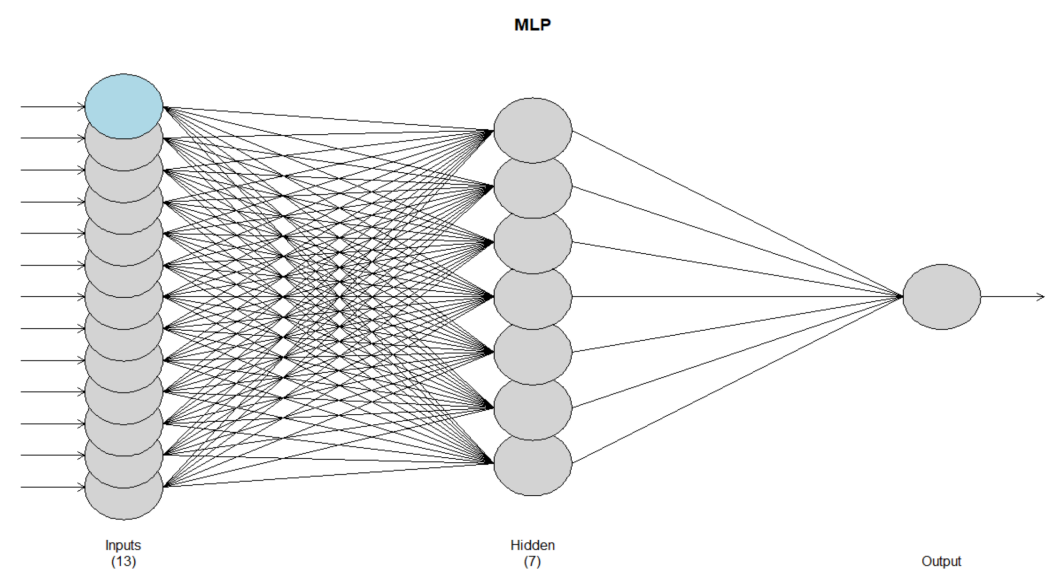

Figure 5. The network architecture of NARX NN model for rainfall.

\subsection{Forecasting Exogenous Variables (Niño 3.4)}

The Niño 3.4 forecasting is conducted with the feed-forward neural network (FFNN). The steps performed are similar to the steps in Section 3.1. The model architecture for the FFNN model for the Niño 3.4 prediction is shown in Table 3.

Table 3. The FFNN model network architecture.

\begin{tabular}{cc}
\hline Unit & Specifications \\
\hline Input unit & 12 unit $(\operatorname{lag} 1,2, \ldots, 12)$ \\
Hidden layer & 1 layer \\
Hidden unit & $1,2,3,4,5,6,7$ unit (trial and error) \\
Output unit & 1 unit \\
\hline
\end{tabular}

Following the formation of the network architecture, the next stage is the process of training and testing and model evaluation. The Niño 3.4 data used in the training process 
were first normalized using the min-max scaling technique with the values of $\mathrm{a}=-0.8$ and $b=0.8$. Using the same training and testing phases as in Section 3.1, we performed seven network architectures with different numbers of hidden units of trial and error. The results for the MAPE value of Niño 3.4 data are shown in Table 4.

Table 4. The error size of the FFNN model.

\begin{tabular}{ccc}
\hline Architecture & Hidden Unit & MAPE Test \\
\hline & 1 & 4.53155 \\
Input unit $=12$ & 2 & 4.501856 \\
Hidden layer $=1$ & 3 & 4.514769 \\
& 4 & 4.500933 \\
& 5 & 4.443294 \\
& 6 & 4.623074 \\
\hline
\end{tabular}

In Table 4, it can be seen that the network architecture that produces the minimum error size is the architecture with twelve input units, one hidden layer, five hidden units, and one output unit or it can be seen as the FFNN model (12-5-1) for the Niño 3.4 with a MAPE of $4.44 \%$ and $R^{2}$ of $95.27 \%$. A visualization of the comparison result of the training process prediction with the testing data according to the ROCV method can be seen in Figure 6 . The following plot is a comparison between the actual data and the predicted data of the FFNN (12-5-1) model for all of the Niño 3.4 data. Figure 6 shows a visualization of the actual and forecast Niño 3.4 data. Figure 7 shows the actual and predicted value of all the Niño 3.4 data.

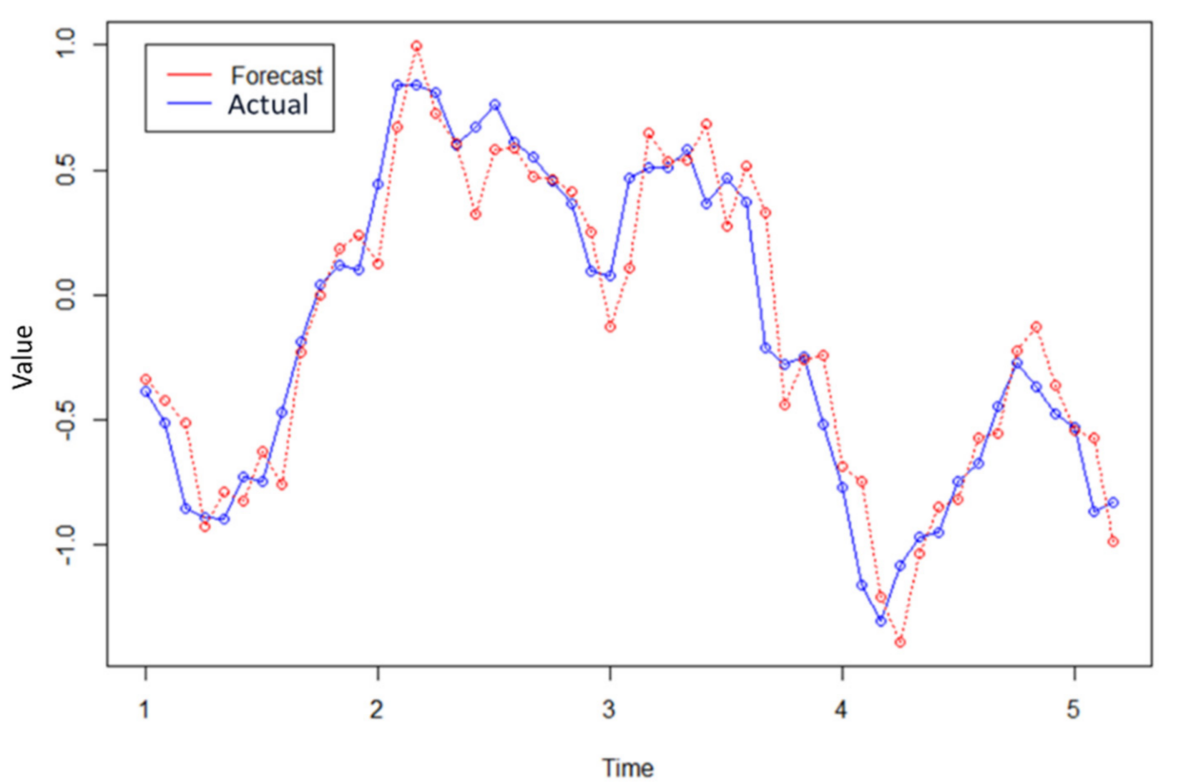

Figure 6. A comparison plot of the training process forecasting results on the Niño 3.4 testing data. 


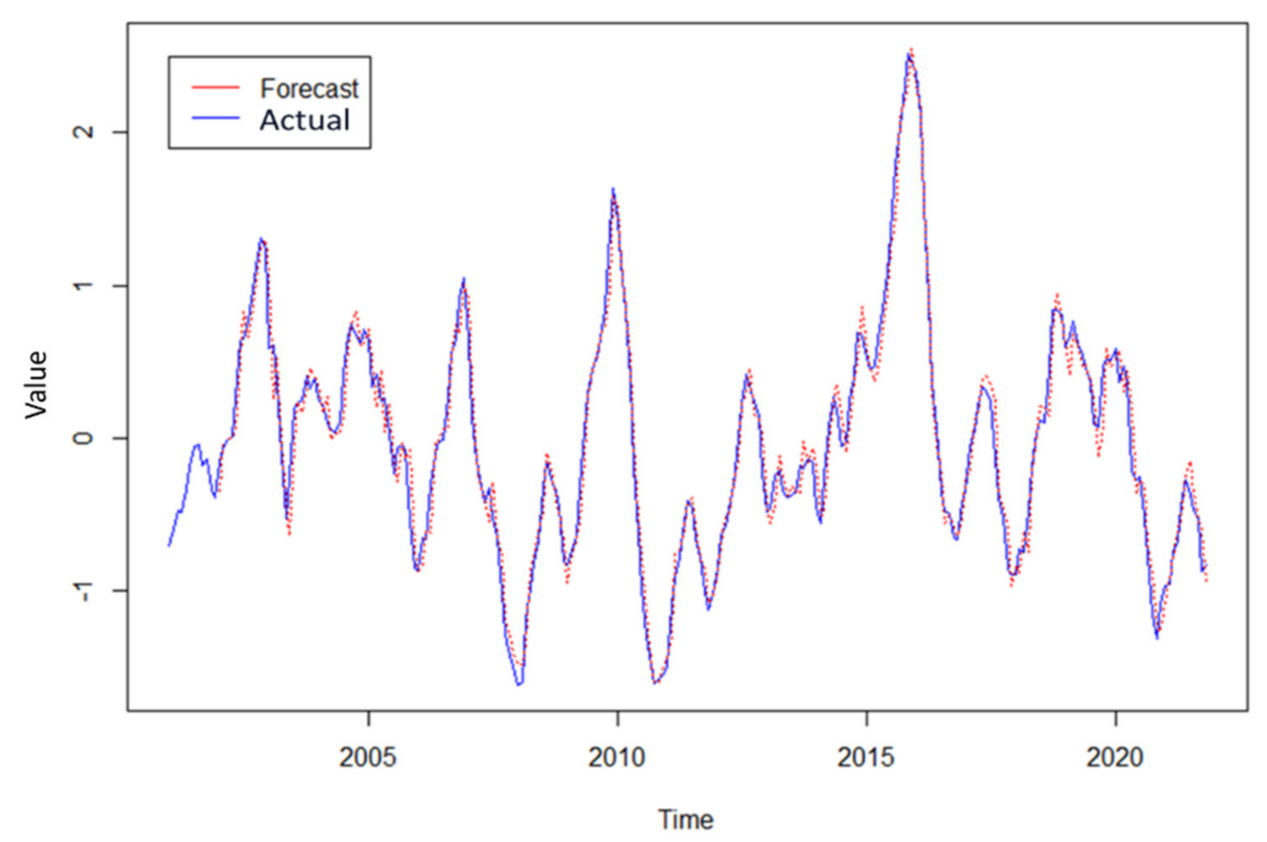

Figure 7. Graphs of the actual and predicted value of all the Niño 3.4 data.

The network architecture visualization of the FFNN model (12-5-1) is shown in Figure 8.

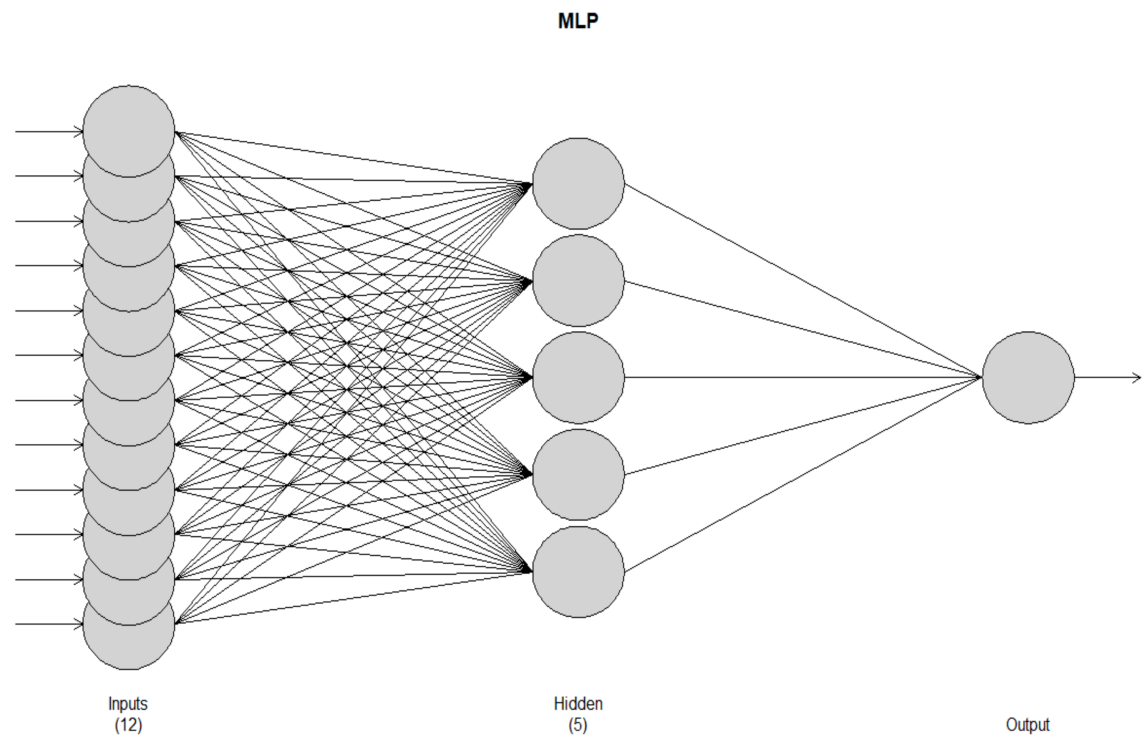

Figure 8. The network architecture of the FFNN model for Niño 3.4.

The FFNN (12-5-1) model from all of the data is used to forecast Niño 3.4. The forecast period for Niño 3.4 is at least as long as the forecast period for the rainfall. In this study, forecasts are conducted for the next six periods and the results of the Niño 3.4 forecast are shown in Table 5. Here, the Niño 3.4 forecast results are combined with the actual Niño 3.4 data to produce 261 combined periods of Niño 3.4 data, comprising 251 periods of actual data, in addition to six periods of the Niño 3.4 forecast results. The combined Niño 3.4 data are used to input the exogenous variables in the best NARX NN model to predict rainfall. 
Table 5. Niño 3.4 forecast results.

\begin{tabular}{cc}
\hline Period & Forecast \\
\hline December 2021 & -0.6212955 \\
January 2022 & -0.6976738 \\
February 2022 & -0.5343275 \\
March 2022 & -0.4814957 \\
April 2022 & -0.3752520 \\
May 2022 & -0.2630829 \\
\hline
\end{tabular}

\subsection{Forecasting the Main Variable (Rainfall)}

In Section 3.1, the process of creating the NARX NN model was carried out using actual data on the rainfall and actual data on the Niño 3.4. Following the receival of the Niño 3.4 forecast results in Section 3.2, the rainfall forecast can be carried out with the best NARX NN model obtained, namely NARX NN (13-7-1). The NARX NN (13-7-1) model is applied to all of the current rainfall data with the combined Niño 3.4 data as the exogenous variable. In Figure 9, a plot is shown between the actual data and predicted data from the NARX NN model (13-7-1) when applied to all of the rainfall data. The rainfall forecast for the next six periods using all of the current rainfall data and the combined Niño 3.4 data are shown in Table 6. In Figure 10, a comparison is shown of the actual data and the forecast results of the rainfall variables and the Niño 3.4 variables.

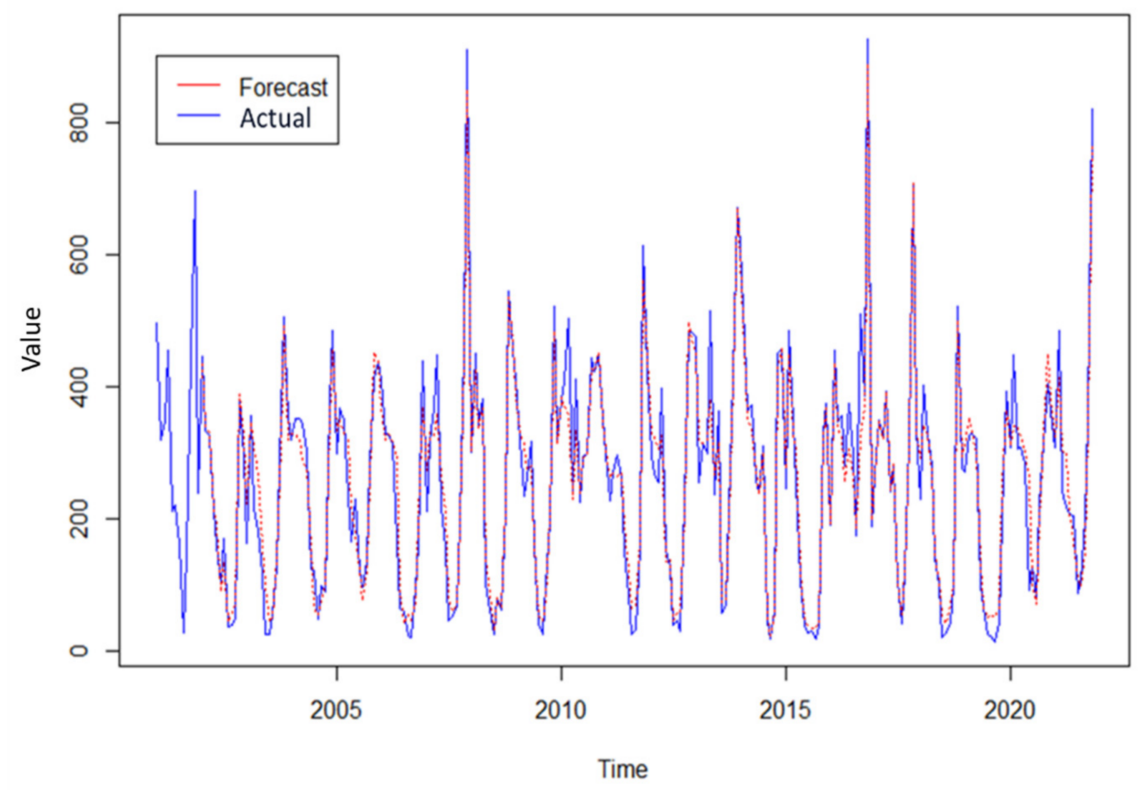

Figure 9. Graph of the actual and predicted values of all rainfall data.

Table 6. Forecast rainfall results.

\begin{tabular}{cc}
\hline Period & Forecast \\
\hline December 2021 & 277.7361 \\
January 2022 & 273.1235 \\
February 2022 & 342.9711 \\
March 2022 & 335.8127 \\
April 2022 & 276.0515 \\
May 2022 & 170.4804 \\
\hline
\end{tabular}




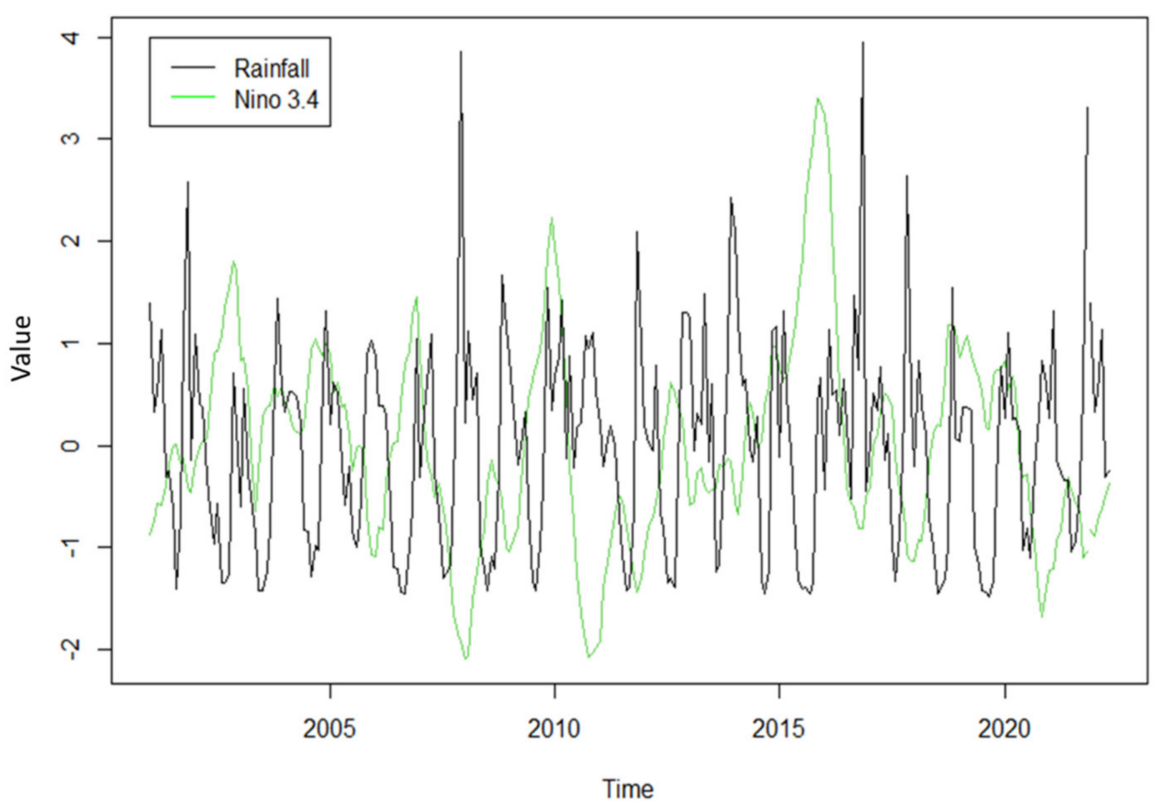

Figure 10. Graph of rainfall and Niño 3.4 results.

Based on the forecast results of the Niño 3.4 index, the prediction is that it will rain or still be in the rainy season for the next 6 months. In Table 6 , it can be seen that the Bandung city rainfall forecast using the NARX NN model provides a prediction that the rainfall will be high in February and March 2022. In Figure 6, it can be seen that the Bandung city rainfall forecast in the period from December-May 2021 provides a fluctuating forecast value, depending on the historical data or rainfall data in the previous period. The forecast results can be used as a reference for relevant agencies in anticipating the possibility of flooding in the city of Bandung and taking extra care, especially during February and March.

\section{Discussion}

The rainfall is a variable that is affected by Niño 3.4. In addition, the city of Bandung has several extreme points with very high rainfall. Very high levels of rainfall can cause flooding. Therefore, in order to cope with the flooding, it is necessary to forecast the rainfall using an exogenous variable, namely Niño 3.4. The forecast results can be used as a reference for relevant authorities to foresee the possibility of flooding in Bandung city.

The amount of data used for the training process affects the ability of the system in the forecasting process. This study uses data with $80 \%$ training data and $20 \%$ testing data [41]. Here, the number of testing data was 51 and the rainfall data were distributed using a number of ROCV methods. The past value of the rainfall and the current value of the Niño 3.4 are used to predict the rainfall. The past value of the rainfall used is 12 lags since the data interval used is monthly data [42], where $Y_{t}$ is influenced by $Y_{t-1}, Y_{t-2}, \ldots, Y_{t-12}$. In addition, $Y_{t}$ is affected by the current Niño 3.4 value, which is referred to as $X_{t}$. Therefore, the number of units used is 12 units, comprising $Y_{t-1}, Y_{t-2}, \ldots, Y_{t-12}$ and $X_{t}$. As the activation function, the tanh activation function in the hidden layer and the linear activation function in the output layer are used [43]. In addition, the training algorithm used is currently Rprop+ [44] and the Niño 3.4 data are used as an exogenous variable.

Based on trial and error, the best model for NARX NN (13-7-1) was obtained with a MAPE value of $6.26 \%$ (Table 2). In Figure 4, a comparison is shown of the training process forecast results to the test data from the rainfall. The best model for the exogenous variable is the (12-5-1) FFNN model with a MAPE value of 4.44\% (Table 4). In Figure 6, a comparison is shown of the training process prognosis results with the test data from the Niño 3.4. The results of this study show that the Niño 3.4 affects the movement of rainfall. In addition, 
the results predict the value of rainfall for the next six periods and Niño 3.4 as input for exogenous variables using the best NARX NN model (Table 5).

Moreover, the results provide suggestions for further research, which can be based on trial and error for the determination of input and hidden layers. There are two alternatives to predict $Y$ with the NARX NN model, namely by predicting the $X$ variable first, as in the study or by building a NARX NN model with lag $X$ (without $X_{t}$ ). Both approaches have limitations. Predicting the $Y$ variable first causes uncertainty, while using lag $X$ assumes that $Y$ is only related to $\operatorname{lag} X$, where the assumption does not necessarily agree with the theory. The forecast results from the neural network method are only available in the form of values. The Bayesian approach, Monte Carlo dropout or resampling with the jackknife and bootstrap methods can be used to obtain forecast results in the form of intervals [45].

There are several studies regarding the physical mechanism, in which these rainfall cycles are increasing over the regions. The authors of [46] investigated the spatiotemporal changes in drought characteristics in Pakistan during the Rabi and Kharif cropping seasons. This study used the nonparametric Mann-Kendall, Sen's Slope, and Sequential MannKendall test methods to determine the significance and historical trends of climate factors on drought. From this study, it was found that the Niño 3.4 index, sea surface temperature, and the multivariate El Niño-Southern Oscillation (ENSO) are factors that strongly influence seasonal droughts across Pakistan. Furthermore, in [47], the research on drought in South Asia related to agriculture is known to indicate that MERRA-2, CPC, FLDAS (soil moisture), GPCC, and CHIRPS (precipitation) are equal and constant across the entire four regions of South Asia (Northwest, Southwest, Northeast, and Southeast). On the other hand, GLDAS and ERA5 remain poor compared to the other soil moisture products and the identified drought conditions in regions one (Northwest) and three (Northeast).

The authors of [48] carried out research on the same topic regarding drought affecting food and agricultural security in South Asia, but with attention to the performance of the evaporative stress index (ESI), vegetation health index (VHI), enhanced vegetation index (EVI), and standardized anomaly index (SAIs). The authors of [49] carried out research on the possible cycles, precursors, and associated mechanisms of drought over Pakistan by paying attention to the rainfall behavior in Pakistan using monthly rainfall data in the period from 1981-2017. The study also analyzed other climatic factors, and it was found that extreme drought events are highly correlated with wind patterns and intrinsic weather systems in The Pacific and Indian Oceans.

The authors of [50] analyzed spatiotemporal changes in air temperature in Myanmar using nonparametric analysis. Based on this study, significant results of the temperature trend are shown. In addition, it is known the Indian Ocean Dipole (IOD) influence on air temperature over Myanmar is more prevalent than the El Niño-Southern Oscillation (ENSO). Another study on the research area of Myanmar is regarding the interdecadal variability in monsoon rainfall [51]. It is known that the Myanmar summer monsoon rainfall is positively correlated with the Atlantic multidecadal oscillation (AMO) and negatively correlated with the Pacific decadal oscillation (PDO).

\section{Conclusions}

In conclusion, the prediction of the rainfall value is conducted using the NARX NN method with the Rprop+ algorithm. The results show that NARX NN (13-7-1) with a MAPE value of $6.26 \%$ and $R^{2}$ of $85.37 \%$ is best suited for the prediction of this phenomenon. To utilize the NARX NN model, it is necessary to forecast the Niño 3.4 with the FFNN using the Rprop+ algorithm. This produces the best FFNN model (12-5-1) with a MAPE value of $4.44 \%$ and $R^{2}$ of $95.26 \%$. In addition, this study produces forecast results for the next six periods, which can be used as a reference for relevant authorities to foresee the possibility of flooding in Bandung city. From the forecast results, it can be concluded that the highest rainfall forecasts in the city of Bandung are in February 2022, and will slowly decrease in March 2022. To prevent hydro-meteorological disasters, such as floods in Bandung city, the community can clear waterways, such as clogged drains, rivers, and dams, as 
well as prepare tools for evacuation [52]. The NARX NN model may be an alternative for the prediction of rainfall value, which has the capability to follow random patterns from rainfall data and capture extreme rainfall values. Meanwhile, the FFNN method can be an alternative for the prediction of Niño 3.4 value.

For the next investigation, predictions can be conducted using other input variables related to precipitation, such as B. AUSMI and WNPMI. Then, the prediction can be conducted using other methods, such as the Bayesian approach, Monte Carlo dropout or resampling with the jackknife and bootstrap methods in the form of intervals [53].

Author Contributions: Conceptualization, R.S.P., T.T. and B.N.R.; Data curation, R.S.P.; Formal analysis, M.D.P., N.S., R.S.P., T.T. and B.N.R.; Methodology, N.S. and M.D.P., R.S.P., T.T. and B.N.R.; Project administration, T.T., R.S.P. and B.N.R.; Resources, N.S., M.D.P., R.S.P., T.T. and B.N.R.; Software, M.D.P., N.S., R.S.P., T.T. and B.N.R.; Supervision, R.S.P.; Visualization, N.S. and M.D.P.; Writingoriginal draft, N.S., M.D.P., R.S.P., T.T. and B.N.R.; Writing-review \& editing, M.D.P., N.S., R.S.P., T.T. and B.N.R. All authors have read and agreed to the published version of the manuscript.

Funding: This research is supported by Department of Statistics, Padjadjaran University and Rector Universitas Padjadjaran who supported this research by Academic Leaderships Grant (ALG) with contract number 1959/UN6.3.1/PT.00/2021.

Institutional Review Board Statement: Not applicable.

Informed Consent Statement: Not applicable.

Data Availability Statement: UCSB CHIRPS v2p0 Monthly Global CHIRPS Precipitation available online: https:/ /iridl.ldeo.columbia.edu/SOURCES/.UCSB/.CHIRPS/.v2p0/.monthly/.global/ .precipitation/X/\%28110.85E\%29VALUES/T/\%28Jan2021\%29\%28Sep2021\%29RANGEEDGES/Y/\%2 87.075S\%29VALUES/ datatables.html (accessed on 13 January 2022) and APCC. Pacific SST Indices Monitoring available online: https://apcc21.org/ser/indic.do?lang=en (accessed on 13 January 2022).

Conflicts of Interest: The authors declare no conflict of interest.

\section{References}

1. Utina, R. Global Warming. Jurnal SAINTEK UNG. 2009, pp. 1-11. Available online: https:/ /repository.ung.ac.id/karyailmiah/ show /324/pemanasan-global-dampak-dan-upaya-meminimalisasinya.html (accessed on 2 February 2022).

2. Iyakaremye, V.; Zeng, G.; Yang, X.; Zhang, G.; Ullah, I.; Gahigi, A. Science of the Total Environment Increased high-temperature extremes and associated population exposure in Africa by the mid-21st century. Sci. Total Environ. 2021, 790, 148162. [CrossRef] [PubMed]

3. Mulyani, A.S. Global Warming, Causes, Impacts and Anticipation. 2021. Available online: http://repository.uki.ac.id/4908/1 /PEMANASANGLOBAL.pdf (accessed on 2 February 2022).

4. Iyakaremye, V.; Zeng, G.; Ullah, I.; Gahigi, A.; Mumo, R.; Ayugi, B. Recent Observed Changes in Extreme High-Temperature Events and Associated Meteorological Conditions over Africa. Int. J. Climatol. 2021. [CrossRef]

5. Sipayung, S. The Spectrum Analysis of Meteorogical Elements in Indonesia. Master's Thesis, Nagoya University, Nagoya, Japan, 1995.

6. Pramudia, A. Climate Dynamics in Indonesia; Agricultural Research and Development Agency: Jakarta, Indonesia, 2020.

7. McBride, M.; Haylock, M.R.; Nicholls, N. Relationships between the Maritime Continent Heat Source and the El Niño-Southern Oscillation Phenomenon Relationships between the Maritime Continent Heat Source and the El Niño-Southern Oscillation Phenomenon. J. Clim. 2003, 0442, 2905-2914. [CrossRef]

8. Sein, Z.M.M.; Ullah, I.; Iyakaremye, V.; Azam, K.; Ma, X.; Syed, S.; Zhi, X. Observed spatiotemporal changes in air temperature, dew point temperature and relative humidity over Myanmar during 2001-2019. Meteorol. Atmos. Phys. 2022, 134, 10-15. [CrossRef]

9. Sein, Z.M.M.; Zhi, X.; Ullah, I.; Azam, K.; Ngoma, H.; Saleem, F.; Xing, Y.; Iyakaremye, V.; Syed, S.; Hina, S.; et al. Recent variability of sub-seasonal monsoon precipitation and its potential drivers in Myanmar using in-situ observation during 1981-2020. Int. J. Climatol. 2021. [CrossRef]

10. Robinson, P.J.; Henderson-Sellers, A. Contemporary Climatology; Routledge: New York, NY, USA, 2014.

11. Tjasyono, B. Meteorologi Indonesia; Meteorology Climatology and Geophysics Council Meteorology, Climatology and Geophysics Agency: Jakarta, Indonesia, 2012; Volume 1.

12. IPRC. International Pasific Research Center. IPRC Climate. 2012. Available online: http:/ /iprc.soest.hawaii.edu/ (accessed on 2 February 2022). 
13. Ina, J.; Ruminta Bayong, T.H.; Atika, L.; Harijono, S.B. The Effect of El Niño, La Niña and Indian Ocean Dipole on Pentad Rainfall in Indonesia. J. Bionatura 2008, 10, 168-177. Available online: https: / $/$ www.google.com $/$ url? sa $=t \& r c t=j \& q=\& e s r c=$ s\&source=web\&cd=\&ved=2ahUKEwjVx92QlfX1AhU3iv0HHZsQBgkQFnoECAwQAQ\&url=https\%3A\%2F\%2Fjurnal.unpad ac.id\%2Fbionatura\%2Farticle\%2Fdownload\%2F7735\%2F3591\&usg=AOvVaw1eWTNIOGVSUyHyXFO-HL1t (accessed on 13 January 2022).

14. Rudiyanto, A. Atmospheric Climate Projection, Bappenas, Jakarta, Indonesia. 2018. Available online: https://lcdi-indonesia.id/ wp-content/uploads/2020/05/Proyeksi-Iklim-Atmosferik (accessed on 2 February 2022).

15. Anisa, K.N. Analysis of the Relationship between Rainfall and El-Nino Southern Oscillation Indicators in East Java Rice Production Centers Using the Copula Approach. J. Sains Seni 2015, 4, 146.

16. Oded, M. Government Agencies Performance, PPIDBandung, Bandung, Indonesia. 2020. Available online: https://ppid. bandung.go.id/wp-content/uploads/2021/07/LKIP-Kota-Bandung-2020 (accessed on 2 February 2022).

17. Jabar. Prov, Bandung City Profile. PPIDBandung, Bandung, Indonesia. 2020. Available online: https://ppid.bandung.go.id/?media_ $\mathrm{dl}=9872$ (accessed on 2 February 2022).

18. Gutomo, M.d.T. Flood and Landslide Natural Disasters and Community Efforts in Mitigating. J. PKS 2015, 14, 437-452.

19. Tempo.co. Hegarmanah, Bandung Hit by Flood. 2008. Available online: https://nasional.tempo.co/read/116481/hegarmanahbandung-diterjang-banjir (accessed on 2 February 2022).

20. Putra, M.A. A Total of 16 Points in Bandung Were Submerged by Floods. 2016. Available online: https://www.cnnindonesia. com/nasional/20161114000828-20-172377/sebanyak-16-titik-di-bandung-terendam-banjir (accessed on 2 February 2022).

21. Kartika, T.; Sulandari, W.; Pratiwi, H. Forecasting rainfall in the city of Bandung using singular spectrum analysis. J. Ilm. Mat. 2021, 8, 56-65.

22. Danung, A. Floods Inundate Six Districts in Bandung Regency. 2020. Available online: https://bnpb.go.id/berita/banjir-rendamenam-kecamatan-di-kabupaten-bandung (accessed on 2 February 2022).

23. UCSB CHIRPS v2p0 Monthly Global CHIRPS Precipitation. 2021. Available online: https://iridl.ldeo.columbia.edu/SOURCES/ .UCSB/.CHIRPS/.v2p0/.monthly/.global/.precipitation/X/\%28110.85E\%29VALUES/T/\%28Jan2021\%29\%28Sep2021\%29 RANGEEDGES/Y/\%287.075S\%29VALUES/datatables.html (accessed on 13 January 2022).

24. APCC. Pacific SST Indices Monitoring. 2021. Available online: https://apcc21.org/ser/indic.do?lang=en (accessed on 13 January 2022).

25. Desouky, M.A.A.; Abdelkhalik, O. Wave prediction using wave rider position measurements and NARX network in wave energy conversion. Appl. Ocean Res. 2019, 82, 10-21. [CrossRef]

26. Zhang, G.; Patuwo, B.E.; Hu, M.Y. Forecasting with artificial neural networks: The state of the art. Int. J. Forecast. 1998, 14, 35-62. [CrossRef]

27. Ghamariadyan, M.; Imteaz, M.A. A wavelet artificial neural network method for medium-term rainfall prediction in Queensland (Australia) and the comparisons with conventional methods. Int. J. Climatol. 2021, 41, E1396-E1416. [CrossRef]

28. Shrivastava, G. Application of Artificial Neural Networks in Weather Forecasting: A Application of Artificial Neural Networks in Weather Forecasting: A Comprehensive Literature Review. Int. J. Comput. Appl. 2012, 51, 17-29. [CrossRef]

29. Pham, B.T.; Le, L.M.; Le, T.-T.; Bui, K.-T.T.; Le, V.M.; Ly, H.-B.; Prakash, I. Development of advanced artificial intelligence models for daily rainfall prediction. Atmos. Res. 2020, 237, 104845. [CrossRef]

30. Diez-Sierra, J.; Jesus, M. Long-term rainfall prediction using atmospheric synoptic patterns in semi- arid climates with statistical and machine learning methods. J. Hydrol. 2020, 586, 124789. [CrossRef]

31. Rahman, S.; Reza, A. Are precipitation concentration and intensity changing in Bangladesh overtimes? Analysis of the possible causes of changes in precipitation systems. Sci. Total Environ. 2019, 690, 370-387. [CrossRef]

32. Ruiz, L.G.B.; Cuéllar, M.P.; Calvo-Flores, M.D.; Jiménez, M.D.C.P. An Application of Non-Linear Autoregressive Neural Networks to Predict Energy Consumption in Public Buildings. Energies 2016, 9, 684. [CrossRef]

33. Ranjit, K.P.; Sinha, K. Forecasting crop yield: A comparative assessment of arimax and narx model. Indian Agric. Stat. Res. Inst. 2016, 1, 77-85.

34. Wunsch, A.; Liesch, T.; Broda, S. Forecasting groundwater levels using nonlinear autoregressive networks with exogenous input (NARX). J. Hydrol. 2018, 567, 743-758. [CrossRef]

35. Boussaada, Z.C. A Nonlinear Autoregressive Exogenous (NARX) Neural Network Model for the Prediction of the Daily Direct Solar Radiation. Energies 2018, 11, 620. [CrossRef]

36. Fausett, L. Fundamentals of Neural Networks Architectures, Algorithms, and Applications; Prentice Hall, Inc.: London, UK, 1994.

37. Cadenas, E.; Rivera, W.; Campos-Amezcua, R.; Heard, C. Wind Speed Prediction Using a Univariate ARIMA Model and a Multivariate NARX Model. Energies 2016, 9, 109. [CrossRef]

38. Chen, R.J.; Bloomfield, P.; Fu, J.S. An evaluation of alternative forecasting methods to recreation visitation. J. Leis. Res. 2003, 35 441-454. [CrossRef]

39. Gao, Y.; Er, M.J. NARMAX time series model prediction: Feedforward and recurrent fuzzy neural network approaches. Fuzzy Sets Syst. 2014, 150, 331-350. [CrossRef]

40. Hyndman, R.J.; Athanasopoulos, G. Forecasting: Principles and Practice; Monash University: Melbourne, Australia, 2018.

41. Rianto, Y.; Kuntoro, A.Y. Prediction of Netizen Tweets Using Random Forest, Decision Tree, Naïve Bayes, and Ensemble Algorithm. Sinkron 2020, 5, 58-71. 
42. Ladiray, D.; Palate, J.; Mazzi, G.; Proietti, T. Seasonal Adjustment of Daily Data. In Proceedings of the 16th Conference of IAOS, Paris, France, 19-21 September 2018; pp. 1-26.

43. Feng, J.; Lu, S. Performance Analysis of Various Activation Functions in Artificial Neural Networks. J. Phys. 2019, 1237, 022030. [CrossRef]

44. Anastasiadis, A.D.; Magoulas, G.D.; Vrahatis, M.N. An Efficient Improvement of the Rprop Algorithm. In Artificial Neural Networks in Pattern Recognition (ANNPR 2003), Proceedings of the First International Association of Pattern Recognition-TC3 Workshop (IAPR 2003), Florence, Italy, 12-13 September 2003; Gori, M., Marinai, S., Eds.; Springer: Berlin/Heidelberg, Germany, 2003; pp. 197-201.

45. Ghoshal, B.; Tucker, A.; Sanghera, B.; Wong, W.L. Estimating uncertainty in deep learning for reporting confidence to clinicians in medical image segmentation and diseases detection. Comput. Intell. 2019, 37, 701-734. [CrossRef]

46. Ullah, I.; Ma, X.; Yin, J.; Saleem, F.; Syed, S.; Omer, A.; Habtemicheal, B.A.; Liu, M.; Arshad, M. Observed changes in seasonal drought characteristics and their possible potential drivers over Pakistan. Int. J. Climatol. 2021. [CrossRef]

47. Shahzaman, M.; Zhu, W.; Ullah, I.; Mustafa, F.; Bilal, M.; Ishfaq, S.; Nisar, S.; Arshad, M.; Iqbal, R.; Aslam, R.W. Comparison of multi-year reanalysis, models, and satellite remote sensing products for agricultural drought monitoring over south asian countries. Remote Sens. 2021, 13, 3294. [CrossRef]

48. Shahzaman, M.; Zhu, W.; Bilal, M.; Habtemicheal, B.A.; Mustafa, F.; Arshad, M.; Ullah, I.; Ishfaq, S.; Iqbal, R. Remote sensing indices for spatial monitoring of agricultural drought in south asian countries. Remote Sens. 2021, 13, 2059. [CrossRef]

49. Hina, S.; Saleem, F.; Arshad, A.; Hina, A.; Ullah, I. Droughts over Pakistan: Possible cycles, precursors and associated mechanisms. Geomat. Nat. Hazards Risk 2021, 12, 1638-1668. [CrossRef]

50. Sein, Z.M.M.; Ullah, I.; Syed, S.; Zhi, X.; Azam, K.; Rasool, G. Interannual variability of air temperature over myanmar: The influence of enso and iod. Climate 2021, 9, 35. [CrossRef]

51. Sein, Z.M.M.; Ullah, I.; Saleem, F.; Zhi, X.; Syed, S.; Azam, K. Interdecadal variability in myanmar rainfall in the monsoon season (May-october) using eigen methods. Water 2021, 13, 729. [CrossRef]

52. Jati, R. Susur Sungai Upaya Cegah Potensi Bahaya Banjir Bandang. BNPB. 2020. Available online: https://bnpb.go.id/berita/ susur-sungai-upaya-cegah-potensi-bahaya-banjir-bandang- (accessed on 2 February 2022).

53. Toharudin, T.; Pontoh, R.S.; Caraka, R.E.; Zahroh, S.; Lee, Y.; Chen, R.C. Employing long short-term memory and Facebook prophet model in air temperature forecasting. Commun. Stat.-Simul. Comput. 2021. [CrossRef] 